\title{
The Nigerian Musical Instrument \\ Production Industry
}

\author{
Sunday Ofuani \\ *http://dx.doi.org// | 0.43 |4/ujah.v I7i3.3
}

\section{Abstract}

The quest for abundant job opportunity and unemployment resolution actually demand economic-diversification approach, which can enhance/advance the development of all the prospective economic industries in Nigeria. The 'Vision 2020' movements equally stress on it in order to achieve its targets. In this limelight, this research examines and assesses the various endeavours through which the Nigerian Musical Instrument Production Industry (NMIPI) contributes to the national economy. Through observation, interview, discussion and evaluation methods, it is identified that although the industry contributes to the Nigerian economy it requires technological, mechanical, cost-effectiveness, financial-viability, trade and industrial development to enhance optimal utilization of all its economic potentials. There is no Gross Domestic Product (GDP) or any official record(s) of the existing economic and cultural inputs of NMIPI. Hence it may be difficult for the Local, States and Federal governments and the populace to appreciate the impacts of the industry by recognizing, supporting, strengthening and making it work effectively. On this backdrop, this paper discusses and evaluates the NMIPI in order to expose its various economic and cultural importances. The problems and prospects of the industry were identified and examined. The findings can serve as basic evaluation information that can help to assess and appraise the economic prospects of NMIPI.

Keywords: Nigerian, musical instruments, production, industry, economic, problems, development, prospect 


\section{Introduction}

Nigeria as a developing country with numerous resources yet with limited prospects for creating new jobopportunities has no other option that can relieve the overstretched concentration on a very few of its sectors and industries than the need to have all its prospective economic sectors and industries recognized, strengthened and working effectively. Recently, the government has realized that economic diversification approach remains the only quick and effective method to advance the economy and creating job opportunities or enhancing the populace, thereby boosting its gross economic stratum to optimal utilization. To actualize this goal within a time frame of the year 2020; several agencies, stakeholders, funds and policies have been put in place to develop and/or revive all Nigerian prospective economic sectors and industries that have been ineffective, neglected, relegated to the background or not recognized as contributor to the national economy.

The Nigerian Musical Instrument Production Industry (NMIPI) is one of the prospective industries that have hitherto received no recognition and support as far as its developmental aids are concern. It is obvious that no one has recognized or put-up reason(s) why it should be part of any developmental programs. The immediate factor that hinders its recognition, support and development is not that the technologists who are involved in the industry are unskilled, unadventurous or unproductive but the veracity that the Federal/States' Ministry of Arts \& Culture and the Ministry of Finance cannot ascertain (through Gross Domestic Product (GDP) and other official data or statistics) the level of existing contributions of the industry to the economic and cultural interests of Nigeria. Due to this negligence it might seem absurd for anyone to convince any developmental agency like National Economic Empowerment and 
Development Strategy (NEEDS), Millennium Development Goals (MDGs) etc. on the perception that NMIPI contributes to the national economy. Thus, the need to validate such perception with national/state statistics that attest its economic contributions remains the best approach. But which Ministry in Nigeria can one find the GDP statistics that features the economic benefits from the industry? So, except by mere natural occurrence it may be impossible for government to appreciate, uphold or support the industry through any of its developmental programs without record evidence of its existing input to the national economy. Husky Millar experiences a related problem in his country - St Lucia. So, he called on the aforementioned ministries for the GDP statistic of the St Lucian's popular music industry but he was laughed at. He rightly notes that "It would be extremely difficult for governments and the population to appreciate the true value of the industry if we are unable to assess the industry's worth as a sector which produces employment."

The negligence of the NMIPI in the national/state GDP indicates that its economic-prospects are left to develop at the pace and financial capacity of the crude technologists that are involved in the industry. Consequently, Nigerians valuable technological skill/talents, knowledge and cultural heritage in the industry are underutilized.

\section{Survey of Nigerian Musical Instrument Production}

Diverse societies, ethnic groups and cultures in Nigeria construct its musical instruments depending on materials (wood, animal hides and skin, metal, seeds and clay resources etc.) available to them coupled with their ability of technology of extraction and construction. But then, crossculture of some Nigerian musical instruments is a normal practice among diverse ethnic groups of Nigeria. 
Wide variety of membrane drums are made in every cultural facet of Nigeria. Yoruba people are renowned maker of talking-drums (lyaalu and gudugudu etc.). The lgbo people are known for their wooden-flute (oja), ngedegwu (xylophone), alo (big metal bell), ikoro (slit drum), udu (potdrum) etc. The Niger-Delta people are famous for thumb piano and bell etc. The bowed string instruments (goge) and trumpet with reed(s) (kakaki) etc. of the Hausa people are not left out'. The Nigerian musical instruments are as multi as its diverse culture, language, dialects and ethnic groups. So that in every Nigerian society or culture, indigenous musical instrument producer(s) can be located ${ }^{2}$. Hence, the industrial activities of one of the major NMIPI workshop-markets ${ }^{3}$ located at the No. 9, Urualla Street, Woliwo, in Onitsha of Anambra State is the focus of this paper as well as the representative of the numerous others across the country.

The workshop-market occupies a land space of about 800 by $700 \mathrm{ft}$. Construction/production and sales of diverse Nigerian musical instruments take place there. Although the Igbo musical instruments are most prevalent in the workshop-market, those of other Nigerian cultures and ethnic groups are scarcely available. The producers/sellers of the musical instruments are Nigerians who did not undergo any formal training of the construction of the instrument(s). In many instances the technology of construction is hereditary while in some other cases it is acquired through apprenticeship by observation and active participation. So most of them construct only the musical instrument(s) they inherited its technology of construction without going beyond the standard of the prototype.

Some of the Nigerian musical instruments that are prevalent in the entire workshop-market are xylophone (the double-slab, multi-slab and chromatic types), wooden bells (okpokolo), slit drums (ekwe/ikoro), metal bells (alo, ogene etc.), 
mgbiligba (bell), ogenephone (chromatic metal-bells) wooden rattles, calabash/gourd rattles, basket rattles, udu (musical pots - the foam-pad and the hand beaten types), varieties of membrane drums (igba, conga, ogwe etc.), thumb piano (ubo $a k a)$, lgbo ethnic wooden flute (oja), and the Yoruba talkingdrums, etc. In addition, wide variety of traditional musicalarts props and costumes are available there.

\section{Tools and Techniques of Construction}

Tools like cutlass, hand saw, file, chisel and mallet are used to cut, bore, hew, scoop and smoothen wood during construction of musical instruments like ekwe, ikoro, ogwe, oja, ngedegwu (xylophone), okpokolo and igbalegede (wooden resonator membrane drums) while sunlight and air are sources of seasoning of wood. For construction of earthenware musical instruments ceramic tools like spade, hand-trowel, pallet, knife and rope etc. are used to mix, cut, erect and shape baked clay until it takes the desired shape of $u d u^{4}$ (pot drum). Seasoning of udu is strictly the terracotta standard, otherwise known as baked-clay. In construction of metal musical instruments bellow-furnace, chisel, pliers, mallet, hammer and shear-scissors are used by the blacksmiths to smelt, liquidize, weaken the metal (in order to re-cast or bend metals to intended shape), cut, hit, open hole on metal or hold metals during heating. Musical instruments like ogene (metal-bell), alo (big metal-bell), udu and mgbiligba are made from the processes. Makers of shaken idiophones like rattles and maracas of diverse type e.g. ichaka (gourd rattle), ekpili (ankle rattle) etc. use common handicraft tools like knife, razor, needle and chisel to bore hole in the materials and weave any intended musical instrument. 


\section{Conservative Thoughts on Nigerian Musical Instruments}

It is observed from discussion sources that some school of thought holds the ideology that the Nigerian musical instruments should be left in its crude state so that their diverse traditional timbre (sound quality) may not be hampered in the processes of redesigning/development. That may be correct, but the reason is too myopic because every aspect of human activities is dynamic. Thus, if these musical instruments are not developed in-tune to contemporary cultural, technological and scientific dynamism, its need might not be felt in generations to come. Uche Okeke could not conceal his observation on Nigerian musical instruments in his foreword to Echezona (198I: v) when he said that

As a designer, I realize the great challenge posed by the exposition of these traditional musical instruments which are as yet not adapted or redesigned for the more sophisticated contemporary Nigerian musicians. Consequently, the instruments remain static museum objects.

While I appreciate the developmental efforts of some professional musical instrument technologists/producers in Anambra State (like Dr Humphrey Nwafor) in redesigning/refining some lgbo musical instruments (especially the xylophone and metalophone). It is quite sad to affirm that Nigerian musical instruments have remained almost static in the crude standard the Nigerian historic periods constructed them. If peradventure contemporary inventors from other worlds' cultures overtake and regenerate any Nigerian musical instrument, its originator/ownership and patent shall not only be lost but also the timbre that we strive to conserve. This is so because everyone will quickly embrace 
the refined-brands and reject/disvalue the crude relatives/prototypes. It should also occur to those in the conservative school of thought that every Western world musical instruments that we all admire and prefer were once crude in state but today they have become product and output of centuries of refinement and development.

\section{The Impacts of the Nigerian Musical Instrument Production Industry}

Despite the underdevelopment challenges facing the industry, its contributions to the economic and culturalidentity interests of Nigeria and its individual citizens are enormous. So, its impacts are viewed in respect to economic perspectives of employment, revenue to government, occupational therapy, recreation/decoration, source of musical sound and cultural identity.

Employment: In the Woliwo-Onitsha workshop-market, over four-hundred (400) Nigerians are actively involved in the construction and trading of the Nigerian musical instruments. These four-hundred persons, the public sector cannot absorb by any stretch. Hence, if a general guessestimate should be made from this data, it then indicates that it is possible that the industry employs over five-thousand (5000) Nigerians across the country. Raphael Ugwu, who is the chairman of the Woiliwo Indigenous Musical Instrument Production Workshop-market Union confirms the role of the industry as to employment resolution by revealing that he is a Poly-technique graduate who could not secure employment in the public sector but NMIPI has employed him for several years now and so, he has no other option than to depend on the income he generates from it. 
Revenue to Government: The technologists and marketers of NMIPI individually/collectively pay diverse taxes to the Local, State and Federal Governments through its various ministries, agencies and revenue officers. During exportation of the musical instruments bought by foreigners duties are charged by Port and Custom Authorities. Foreigners who tour Nigeria to view some of these musical instruments and/or carry out research on them bring a lot of money along and spend it in Nigeria. So, the Nigerian musical instrument industry being a valuable tourists' attraction invariably adds to the Nigerian economy.

Occupational Therapy: Some handicapped Nigerians are found in the handicraft department of the indigenous musical instruments making. Weaving of diverse rattles, maracas etc. are mostly done by this set of people. However some deaf and/or dumb and lame citizens are active in the construction of other serious and long process musical instruments like ekwe, alo etc. These handicapped persons do not only earn income for themselves. It is observed that as their minds get occupied with such works, thinking about their sickness becomes obscured. In this, Irivwieri (2009) notes that

Many Hospital patients as well as the blind and permanently bedridden, take part in handicraft programs. A patient who tools often is too busy to think about his illness. Special organizations train these people on various crafts and help them to sell the articles they make. In this way, patients and handicapped people can earn income. (I6)

Source of Musical Sound: Although diverse individuals and cultures have its preferred musical styles/type(s), music is cherished by everyone - even animals. Consequently it is a 
fundamental demand by individuals, families, organizations and in various occasions/ceremonies. Musical sounds generate from musical instrument and/or human voice/body. Thus, African vocal (folk, ethnic, contemporary, popular and art) music of Nigeria are accompanied with indigenous musical instruments in different settings and contexts. For pure traditional instrumental music ensemble, the traditional musical instruments remain the primary source of its musical sound. Even in this computer age, its sound is still a viable means of communal signal, telegraph, information dissemination and advertizing in some villages/towns.

Cultural Identity: Continents, Nations, Ethnics and Societies are often identified by the sound of its musical instrument(s). In fact, to certain extent a people or culture that is not known for a particular musical instrument is deficient in musical identity. Sounds of the iyaalu/gudugudu drums in a musical performance automatically create an impression that the music is of Yoruba origin even when it may not. The conclusion is simply drawn from the application of talking-drum(s) which the Yoruba people are known for. In that way, the music of lgbo people is easily identified through the sound of oja, udu and alo etc. The clanking sound of bells, the sonorous sounds of the thumb piano and energetic handclap are notable instrumental features in the music of the Niger-Delta people. The creaking melodious sound of the goge and the reedy sound of the kakaki send a signal of Hausa music. Though, the equivalents of these instruments are found around other nations of Africa, the sounds of Nigerian music as a complex-whole are identified by other African nations and the entire world through the sound organization and performance mode of its musical instruments.

Artistic designs ${ }^{5}$ that indicate the symbols and codes of certain activities (like religion, occupation and culture etc.) of 
any society are found engraved, carved or painted on some musical instruments. The artistic designs tell a decodable viewer the important things he may need to know about the people and society. Consequently, a society can be identified through the decodable symbol(s).

The regalia of any King or chief in Nigerian cultures (for example the lgbo) is not completed without the elephant tusk trumpet/horn, gourd trumpet or animal horn trumpet being held by him or blown by his royal entourages. This is a traditional means of royal identity and a symbol of authority. Euba (1977: 7) confirms this practice among the Northern States, Western regions and Isoko Kings when he asserted that "Other instruments are reserved for royalty, such as the long trumpets commonly played for Emirs in the Northern States and which are also played for Yoruba kings (for example, the Alaafin of Oyo and the Alake of Abeokuta). The Ogba, an ivory horn, forms part of the regalia of an Isoko village head chief'.

\section{Source of Recreation and Decoration: Diverse} individuals recreate by viewing and imagining the physical aesthetics, ethnic and cultural philosophies involved in the construction of any traditional musical instrument. There are those who use them essentially as decoration, symbol or sign of identity in offices, royal palaces, theaters and homes etc. Amateur technologists who enjoy seeing their handiwork being appreciated are often found constructing some musical instruments with less complicated and tedious construction processes. Primarily, these sets of people enjoy making the musical instruments because they get excited when their work is being appreciated or used. 


\section{Problems within the Industry}

The various problems that gloom NMIPI industrialization efforts are assessed base on its labor, costeffective, financial viability, mechanization and trade and industry.

Labor: There is no systematic division of labor in NMIPI. Over ninety-five percent (95\%) of manual labor is involved in every musical instrument constructed. In terms of mechanization this is not an appreciable industrial potential. Imagine hewing and scooping for several days to make hollow in a log of wood when constructing resonator for igba or ekwe. Aluminum and metal materials are manually smelted to construct udu and alo respectively. Woods are manually bored with hot knoll/chisel to make oja and make holes in xylophone slabs. Woods are manually seasoned for several months to construct xylophone slabs, slit drum and other wooden musical instruments. Animal skins are manually stretched on the surface(s) of resonator to make various membrane drums. Worst of all, is the common use of machete/cutlass to cut large logs/trunk of wood during the construction of wooden musical instruments. Whereas all these processes of manual labor are mechanically possible.

Cost Effective: The prices at which indigenous musical instruments are sold are relatively low when compared with the tedious manual-labor, time involved for construction and the value of Naira. Cost ineffectiveness in the industry is most apparent in the prices of wooden musical instruments where log of wood has to be cut, hewed and scooped for several days to realize hollow resonator(s). Ekwe, which takes up to two to three months to season, hew and scoop before it is completed is just sold for Three-Thousand Naira (N3, 000). Although its price varies according to their different 
sizes, the biggest types found in the workshop-market varies between 10, I1, 12, 14, 17 and 26 inches in diameter and 17, 19, 21 24, 32 and 48 inches of length respectively, but none cost above Seven-Thousand Naira (N7, 000).

Although in the long-run, the technologists make some tangible amount of income but not as they would if they are introduced to mechanical production method. In addition, mechanical technique contributes an appreciable refined degree to the physical aesthetic of any product. Otherwise, it can enhance the renaissance of indigenous musical instruments towards a refined and standardized state/quality that can proudly face the global musical instrument market scene, which should be an addition to Nigerian national economy and maximization of cost-effectiveness and elastic job opportunity for the populace. Beyond doubt, the sounds (timbre) of these musical instruments are exotic and awesome. But there is need for its outward refinement and standardization to enable it to attract huge demand in the global musical instrument scene. Until this is achieved, the cost of Nigerian musical instruments may remain ineffective.

Financial Viability: Even though the technologists make money income that can settle their (individual and/or families') fundamental daily expenses and bills, the industry is not financially viable and the reason is not that it has got no potentials of financial viability. The accumulated effects of having the industry underdeveloped keep yielding costineffectiveness of their products - which in turn hinders the attainment of financial viability amongst the technologists and the industry in its totality. The non-financial viability in no small extent affects the technologists' occupational prestige, standard of living and reasonable response towards their civic obligation of tax payment which would have been an addition to the state/national income. More pronounced amongst the 
effects of its non-financial viability is their inability to acquire modern power tools and machines.

Mechanization: Lack of fund is a challenge here. Contemporary power tools or machines like panel saw, band saw, drill press, spindles sander, chain saw, wood bark remover, filling/smoothening machine, sprayer and electric kiln seasoning machine etc. are obviously lacking in the workshop-market. But if these machines are acquired and used the prevailing human manual labors, fatigue and time spent in construction of the instruments will be reduced thereby gearing and improving the entire industry toward a real industrial quantity and quality production outputs of diverse musical instruments. Mechanization would also add some appreciable degree of refined, finished and polished look on the outward appearance of Nigerian musical instruments.

Trade and Industry: Domestic trade of the musical instruments is more common. Diverse churches, social groups, cultural music and dance groups, schools and institutions, Federal/States' Ministries of Art, Culture and Tourism, Royal Courts, individuals etc. clamor at the workshop-market to demand for the musical instruments according to their needs. Some traders who are engaged in trading of the instruments on wholesale and retail bases are great merchants. They travel far and near across the country supplying these instruments in various markets of Nigerian towns and cities. Thus, there is rarely a standard Nigerian market that does not have a section where the indigenous musical instruments are exhibited and sold.

Foreign trade of the Nigerian musical instruments is slight and rare. Nevertheless, special requests and purchases are made occasionally by foreigners from other world 
cultures. The technologists and traders in the workshopmarket site reveal that foreigners often call in the workshopmarket to demand/purchase some of the musical instruments. Some European and American musical ensembles have also featured the udu, ogene, igba, bongos (three in one), iyaalu/gudugudu (talking drums), etc. and most of which were bought from Nigerian musical instrument workshop-market. This also attests that the timbres (sound qualities) of Nigerian musical instruments (even at their crude state) appeal musicians, music lovers and music audience of diverse world cultures across the globe. Since the instruments' timbre is of global acceptance it is then an opportunity to trade the product across the globe and influence the world music with Nigerian musical instruments. On the other hand, trading these musical instruments in quantity outside Nigerian boarders remains a problem due to lack of industrialization in respect to mechanization, refinement, packaging, standardization, division of labor that brings about massive production in quantity. If trade and industry of the Nigerian musical instruments is to be completely developed, Uzoagba in Osamudiamen (2009: 50) opines that "it is imperative to recognize in Nigeria that the desire to make things beautiful must be as the desire to make them useful." Mbahi in Osamudiamen (2009: 50), collaborates it when he observes that "equally important, is the aesthetic quality of the production, and such relationship seems lacking in "made in Nigeria' products."

The national policy that discourages exportation of indigenous art works in massive quantity is equally applicable to exportation of Nigerian musical instrument because it also serves as artifact. This policy in addition, hinders reasonable exportation of the products to the other world cultures. 


\section{Conclusion and Suggestions}

The Nigerian musical instrument production industry has been examined and assessed with strong evidence that proves that it is prospectively economical. Given its economic role of creating job or employment opportunity and revenue to government; medical role of occupational therapy; recreational role of enjoyment and decoration; musical role of source of musical sound and the cultural role of identity, it is obvious that NMIPI contributes towards national economic and cultural development. It is evident that there are abundant underutilized employment, trade and financial prospects stocked in the industry but these are hindered by its underdeveloped state. So, until developmental efforts are carried out in the industry the prevailing gross manual labor, cost-ineffective, non financial viability, zeromechanization and the ineffective trade and industry will remain problems that hinder and gloom its industrial efforts. It is therefore important that Nigerian governments of all levels should recognize and support the advancement of NMIPI through its various developmental programs.

Nigerian musicologists, engineers, researchers, metallurgist, woodworkers and xylographers, inventors, companies and individuals should extend/direct their professional researches, experiments and investments towards the Nigerian musical instruments production industry through liaising approaches. Finally, if effort(s) is not geared towards improving the musical instruments within this country, one thing is sure and that is 'change'! As such, let it not surprise anyone in a couple of decades or by next century, when researchers and inventors from other continents succeed in refining some of these musical instruments and claim its ownership. Hence, it is indisputably ideal that whenever any Nigerian musical instruments are being refined/improved upon, its relatives/prototypes should 
be collected in their crude state and conserved in the museum as a point of reference in time to come.

\section{Notes}

I. It is not within the scope of this paper to enumerate all the Nigerian musical instruments produced in diverse cultural facets of Nigeria, so it is pertinent to breach it.

2. The producers and traders of various Nigerian musical instruments can be possibly located in all the villages, towns and cities of Nigeria.

3. It is called 'workshop-market' because the production and sales of the musical instruments are carried-out within the same site.

4. In recent decades there is a commendable change of its production material. Aluminum is now used for its construction instead of the usual clay-soil which lacks durability.

5. The photographs of artistically designed Nigerian musical instruments are extensively demonstrated in: Echezona, W.W.C. (198I) Nigerian Musical Instruments. U.S.A: Apollo Publishers Ltd.

\section{Sunday Ofuani}

Department of Music Delta State University, Abraka, Nigeria

\section{References}

Aig-Imoukhuede, F. (1988). Exploiting Nigrian's Cultural Heritage for Nation Building in Tapping Nigeria's Limitless Cultural Treasures. Lagos: National Council for Arts and Culture. pp.3-17.

Euba, A. (1977). An Introduction to Music in Nigeria. Nigerian Music Review, No. I. Akin Euba (ed.). Department of Music, Ile-lfe, Nigeria. Pp. I-24. 
Echezona, W. W. C. (1963). Ibo Musical Instruments in Ibo

Culture. Ph.D Thesis, Michigan State University.

Echezona, W. W. C. (I98I). Nigerian Musical Instruments.

U.S.A: The Apollo Publishers Ltd.

Husky M. (n.d.). Local Music and National Development: Some Observations, Challenges, and Prospects Part I. Accessed on 07/03/20II:

http://huskyl.stmarys.ca/ hmillar/lmusic.htm

Irivwieri, G. O. (2009). Arts and Crafts as Springboard for

Sustainable Development and Industrialization in

Nigeria. International Journal of Creativity \& Technical

Development. Ukpong, E.C. (ed.). Vol. I. ICIDR pp.I18.

Lawal, B. (1989). Art, Technology and the 2 Ist Century:

Strategies and Prospects for Nigeria. In Creative

Dialogue. Society of Nigerian Artists at 25, Dele Jegede (ed.) Lagos: Society of Nigerian Artistsat. pp.

$3 \mathrm{I}-38$

Mackay, M. (1950).The Traditional Musical Instruments of

Nigeria. Nigerian Field, XV,iii, pp. I I 4

Oloidi, O. (1989).Art, Technology and the 2 Ist Century: The

Nigerian Situation. In Creative Dialogue. Society of

Nigerian Artists at 25, Dele Jegede (ed.) Lagos:

Society of Nigerian Artists. Pp.4I-43.

Osamudiamen, I. O. (2009). Integrating Visual Arts and

Science in Tertiary Institutions in Nigeria for a

Sustainable Technologcal Development. International Journal of Creativity \& Technical Development. Ukpong, E.C.(ed.). ICIDR. Pp.46-53.

Willian B. (1953). Drums of the Yoruba of Nigeria, (annotated).

LP Records. Ethnic Folkways Library, Pp.44I 


\section{Discussion/Interview}

Ugwu, Raphael (is the chairman of the "Woliwo-Onitsha Indigenous Musical Instruments Workshop-market Union': No. 9, Urualla Street, Woliwo, Onitsha, Anambra state) 05/02/20 I I. 